\title{
ANALISIS VEGETASI TUMBUHAN BERKAYU \\ PADA KAWASAN HUTAN TROPIS DATARAN RENDAH CAGAR ALAM PEGUNUNGAN WONDIWOI
}

\section{(Woody Plant Vegetation Analysis in the Low Land Tropical Forest of Pegunungan Wondiwoi Nature Reserve)}

\author{
Fahrid Gian Cinda ${ }^{1}$ Novita Panambe ${ }^{1 凶}$ dan Mariana H. Peday ${ }^{1}$ \\ Jurusan Kehutanan, Fakultas Kehutanan Universitas Papua Manokwari, Papua Barat, \\ 98314. Tlp/Fax: +62986211065. \\ ${ }^{\bowtie}$ Penulis Korespondensi: Email: n.panambe@yahoo.com \\ Diterima: 2 Mar 2019| Disetujui: 30 Mar 2019
}

\begin{abstract}
Abstrak
Penelitian ini bertujuan untuk mengetahui struktur dan komposisi jenis tumbuhan berkayu pada kawasan hutan dataran rendah Cagar Alam Pegunungan Wondiwoi. Metode yang gunakan adalah metode deskriptif dengan teknik survei dan observasi lapang melalui pendekatan kualitatif dan kuantitatif. Data yang dikumpulkan meliputi struktur dan komposisi tumbuhan berkayu dengan menggunakan teknik jalur berpetak lanjut. Hasil penelitian didapatkan 260 jenis tumbuhan berkayu yang terdiri dari 57 famili. Pada fase semai terdapat 168 jenis terdiri dari 52 famili, pancang 172 jenis terdiri dari 51 famili, tiang 138 jenis terdiri dari 39 famili dan pohon 136 jenis terdiri dari 39 famili. Pada fase semai didominasi oleh jenis Pometia pinnata dengan INP $11,247 \%$, fase pancang didominasi oleh jenis Pometia pinnata dengan INP 9,727\%, fase tiang didominan oleh jenis Litsea timoriana dengan INP $14,603 \%$ dan fase pohon didominasi oleh jenis Pometia pinnata dengan INP 20,248\%.
\end{abstract}

Kata kunci: struktur dan komposisi, fase pertumbuhan, INP, dominansi, hutan tropis dataran rendah

\begin{abstract}
This study focuses on identifying structure and composition of woody plant species in the low land tropical forest of Pegunungan Wondiwoi nature preserve area. The descriptive method has been chosen through survey and field observation techniques by way of quantitative and qualitative approaches. For structure and composition data collection, a continue systematic sampling procedure has been applied. The result revealed 260 woody plant species from 57 families were found in the area. In further, at seedling stage, there were 168 species from 52 families, at sapling stage, there were 172 species from 51 families, at pole stage, there were 138 species from 39 families, and at tree stage, there were 136 species from 39 families. In addition to dominance at seedling stage was Pometia pinnata with the IVI score of $11.247 \%$, at sapling stage was Pometia pinnata with the IVI of $9.727 \%$, at pole stage was Litsea timoriana with IVI score of $14.603 \%$, and at tree stage was Pometia pinnata with the IVI score of $20.248 \%$.

Keywords: structure and composition, growth phase, IVI, dominance, tropical lowland forest
\end{abstract}




\section{PENDAHULUAN}

Hutan merupakan kumpulan pepohonan yang tumbuh rapat beserta tumbuh-tumbuhan memanjat dengan bunga yang beraneka warna yang berperan sangat penting bagi kehidupan di bumi ini. Ahli ekologi mengartikan hutan sebagai suatu masyarakat tumbuhtumbuhan yang dikuasai oleh pohonpohon dan mempunyai keadaan lingkungan berbeda dengan keadaan diluarnya. Fungsi hutan adalah menjaga mutu dan keseimbangan lingkungan hidup terutama untuk kepentingan umat manusia (Arifin 2001).

Hutan Papua termasuk dalam kawasan melanesia yang memiliki keanekaragaman hayati yang sangat tinggi, diperkirakan terdapat $25.000-$ 30.000 jenis tumbuh-tumbuhan yang ada di hutan Papua (Johns 1997; Lekitoo et al. 2017). Berdasarkan Keputusan Menteri Kehutanan No. SK.783/Menhut-II/2014 tetang Kawasan Hutan dan Konservasi Perairan Provinsi Papua Barat memiliki luas kawasan hutan dan konservasi perairan \pm 9.713.137 (Kementerian Kehutanan 2014).

Kabupaten Teluk Wondama terletak pada $0^{0}, 15^{\prime \prime}$ hingga $3^{0}, 25^{\prime \prime}$ lintang selatan dan $132^{\circ}, 35^{\prime}$ ' hingga $134^{0}, 45^{\prime}$ ' bujur timur (BPS 2015). Berdasarkan informasi spasial kehutanan Provinsi Papua Barat 2015, luas kawasan hutan Kabupaten Teluk Wondama berdasarkan fungsinya adalah 1.159.057 ha. Kabupaten Teluk Wondama memiliki luas kawasan hutan terbesar di Provinsi Papua Barat bila di bandingkan dengan kabupaten kabupaten lainnya.

Cagar alam adalah kawasan suaka alam yang keadaan alamnya mempunyai kekhasan tumbuhan, satwa, dan ekositem tertentu yang layak untuk dilindungi dan dalam perkembangannya diusahakan secara alami. Adapun usaha untuk melindungi flora dan fauna yang memiliki ciri khusus tersebut dilaksanakan suatu pengembangbiakan secara in-situ (pada habitat asli) dan ex-situ (di luar habitat asli). Namun, konservasi ex-situ sangat sulit dilakukan bila tidak didukung oleh keberadaan daerah sekitarnya. Sebab, kehidupan jenis flora dan fauna secara alami mengalami interaksi dengan ekosistem alaminya dalam kehidupannya.

Cagar Alam Pengunungan Wondiwoi merupakan salah satu dari 16 Cagar Alam yang berada di Provinsi Papua Barat. Cagar Alam Pegunungan Wondiwoi berada pada Kabupaten Teluk Wondama berdasarkan ketetapan Menteri Kehutanan Menhut/No.595/Kpts-II/1992 ditetapkan sebagai kawasan Konservasi yang difungsikan sabagai Cagar Alam dengan luasan $79.500 \mathrm{Ha}$ dengan elevasi ketinggian $0-2222 \mathrm{~m}$ dpl dengan bentuk topografi berbukit (BKSDA Papua Barat 2011).

Analisis vegetasi adalah cara mempelajari susunan (komposisi jenis) dan bentuk (struktur) vegetasi atau komunitas tumbuh-tumbuhan. Salah satu cara dalam analisis vegetasi adalah dengan menggunakan metode jalur atau transek. Cara ini paling efektif untuk mempelajari perubahan keadaan vegetasi menurut keadaan tanah, topografi, dan elevasi. Jalur-jalur contoh dibuat memotong garis-garis topografi (Soerianegara dan Indrawan 1982).

Analisis vegetasi merupakan studi untuk mengetahui struktur dan komposisi dari tumbuh-tumbuhan di hutan. Dari hasil kegiatan analisi vegetasi kita akan mendapatkan informasi mengenai jumlah jenis, volume tegakan, pola sebaran, 
frekuensi, kerapatan, indeks nilai penting (INP) dan indeks keragaman tumbuhan yang terdapat dalam suatu kawasan hutan. Tujuan dari penelitian ini adalah untuk mengetahui struktur dan komposisi jenis tumbuhan berkayu yang terdapat di kaswasan hutan dataran rendah CA Pegunungan Wondiwoi.

\section{METODE PENELITIAN}

\section{Tempat dan Waktu}

Penelitian ini dilaksanakan pada kawasan hutan dataran rendah CA Pegunungan Wondiwoi dengan focus area penelitian pada Kampung Dotir. Penelitian ini berlangsung selama 1 bulan yang dimulai dari tanggal 20 November s/d 27 Desember tahun 2016. Adapun objek yang diamati dalam penelitian ini adalah jenis-jenis tumbuhan berkayu pada kawasan hutan dataran rendah CA Pegunungan Wondiwoi.

\section{Metode Penelitian}

Metode yang digunakan dalam penelitian ini adalah metode deskriptif dengan teknik survei dan observasi lapangan dengan menggunakan pendekatan kuantitatif dan kualitatif (Kusmana 1997). Metode deskripsi kuantitatif dilakukan dalam beberapa tahap penelitian yaitu: penelitian lapangan, penelitian pustaka dan analisis data. Sedangkan metode deskripsi kualitatif adalah penjelasan untuk datadata yang bersifat kualitatif seperti data keadaan umum lokasi penelitian dan datadata dari instansi terkait mengenai pengelolaan CA Pegunungan Wondiwoi.

\section{Variabel Pengamatan}

Variabel yang diamati adalah struktur dan komposisi tumbuhan berkayu yang berada pada kawasan hutan dataran rendah CA Pegunungan Wondiwoi. Data struktur yang dikaji meliputi fase semai, pancang, tiang dan pohon dengan data yang dikumpulkan adalah jumlah jenis, jumlah individu, diameter batang, tinggi bebas cabang dan tinggi total untuk menghitung kerapata (K), kerapatan relatif (KR), frekuensi (F), frekuensi relatif (FR), dominansi (D), dominansi relatif (DR) dan indeks nilai penting (INP). Sementara data komposisi yang dikumpulkan antara lain nama jenis (nama ilmiah) dan famili.

\section{Tahapan Peneltian}

Penelitian ini dilakukan berdasarkan prosedur berikut:

1. Sebelum mengadakan pengumpulan data, dilakukan pengamatan lapangan pada lokasi atau kawasan hutan yang akan dilakukan penelitian dengan tujuan melihat secara umum keadaan dan komposisi tegakan serta kondisi lingkungan lainnya.

2. Menentukan lokasi penelitian.

3. Luas kawasan hutan yang akan diteliti \pm 20 ha. Pengamatan akan dilakukan pada kawasan hutan seluas 4,2 ha (IS = $21 \%$ ).

4. Membuat titik ikat.

5. Membuat jalur pengamatan Base line dengan azimuth $180^{\circ}$ dan jalur pengamatan $90^{\circ}$, jarak antara titik ikat ke base line $10 \mathrm{~m}$, dan jarak antara jalur pengamatan $20 \mathrm{~m}$. Panjang jalur pengamatan $220 \mathrm{~m}$ dan jumlah jalur pengamatan sebanyak 10 jalur, dengan masing-masing petak mempunyai lebar jalur 20. Pada jalur $1-5$ dibuat 10 petak pengamatan dan $6-10$ akan di buat 11 petak pengamatan. Sehingga jumlah petak pengamatan adalah 105 petak (atau sensus untuk fase pertumbuhan pohon). Selanjutnya akan 
dibuat petak-petak pengamatan sebagai berikut :

$>$ Semai dengan ukuran petak $2 \times 2$ $\mathrm{m}$, intensitas sampling (IS) $=1 \%$

Pancang dengan ukuran petak $5 \times 5$ $\mathrm{m}$, intensitas sampling (IS) $=6,25 \%$

Tiang dengan ukuran petak $10 \times 10$ $\mathrm{m}$, intensitas sampling (IS) $=25 \%$

Pohon dengan ukuran petak $20 \times 20$ $\mathrm{m}$, intensitas sampling (IS) $=100 \%$

6. Untuk mengetahui potensi tumbuhan berkayu, berdasarkan besar kecilnya diameter batang adalah sebagai berikut :

- Fase semai, yaitu sejak perkecambahan sampai tinggi 1,5 $\mathrm{m}$.

$>$ Fase pancang, yaitu fase pertumbuhan permudaan dengan tinggi diatas 1,5 meter dan diameter batang kurang dari $10 \mathrm{~cm}$.

Fase tiang, yaitu fase pertumbuhan dengan ukuran diameter $10 \mathrm{~cm}$ sampai $19 \mathrm{~cm}$.

Fase pohon, yaitu fase pertumbuhan dengan ukuran diameter batang lebih dari $20 \mathrm{~cm}$.

Pengumpulan data vegetasi hutan dilakukan dengan metode sampling untuk fase semai, pancang dan tiang serta sensus untuk fase pohon dengan teknik jalur berpetak lanjut (continue systematic sampling method). Pada setiap plot, diidentifikasi jenisnya serta dihitung jumlah individu masing-masing jenis.

\section{Pengumpulan Data}

Data yang dikumpulkan dalam penelitian ini terdiri dari data primer dan data sekunder. Data primer meliputi data inventarisasi tumbuhan yaitu untuk fase semai dan pancang data yang dikumpulkan adalah jenis, jumlah jenis dan jumlah individu, sedangkan untuk fase tiang dan pohon data yang dikumpulkan yaitu jumlah jenis, jumlah individu, tinggi dan diameter. Jenis tumbuhan yang diamati langsung diidentifikasi di lapangan dengan bantuan jasa pengenal jenis. Data sekunder meliputi topografi, tanah (fisik dan kimia), iklim (suhu dan kelembaban).

\section{Pengolahan Data}

Data hasil penelitian yang telah dikumpulkan kemudian diolah untuk mendapatkan indeks nilai penting (INP) yang berguna untuk menentukan dominansi jenis tumbuhan berkayu yang terdapat pada kawasan hutan CA Pegunungan Wondiwoi Kabupaten Teluk Wondama Provinsi Papua Barat. Nilai penting diperoleh dari penjumlahan kerapatan relatif, frekuensi relatif, dan dominansi relatif. Sehingga kita bisa dapat mengetahui potensi tumbuhan berkayu yang berada pada hutan dataran rendah CA Pegunungan Wondiwoi. INP diketahui dengan menggunakan rumus perhitungan analisis vegetasi menurut Soerianegara dan Indrawan (2005), sebagai berikut:

a) Kerapatan (K) dan kerapatan relatif (KR). Kerapatan merupakan jumlah individu spesies per satuan ruang. Kerapatan spesies ke- $i$ dapat dihitung sebagai $\mathrm{K}-i$ dan kerapatan relatif setiap spesies ke- $i$ terhadap kerapatan total dapat dihitung sebagai KR-i. rumus untuk menghitung kerapatan dan kerapatan relatif adalah sebagai berikut: 


$$
\begin{aligned}
\operatorname{Kerapatan}(K) & =\frac{\text { jumlah } \text { individu suatu jenis }}{\text { luas plot conoh }} \\
\text { Kerapatan Relatif }(K R) & =\frac{\text { kerapatan dari suatu jenis }}{\text { kerapatan seluruh jenis }} \times 100 \%
\end{aligned}
$$

b) Frekuensi (F) dan frekuensi relatif (FR). Frekuensi merupakan proporsi antara jumlah sampel plot yang berisi suatu spesies tertentu terhadap jumlah total sampel. dengan nilai frekuensi dapat menggambarkan fase penyebaran dan pola sebaran spesies di dalam habitatnya. rumus dari kerapatan adalah sebagai berikut dominansi (D) dan dominansi relatif(DR).

$$
\begin{aligned}
& \text { Frekuensi }(F)=\frac{\text { jumlah plot ditemukan suatu jenis }}{\text { jumlah seluruh plot }} \\
& \text { Frekuensi Relatif }(F R)=\frac{\text { frekuensi suatu jenis }}{\text { frekuensi seluruh jenis }} \times 100 \%
\end{aligned}
$$

Dominansi merupakan proporsi antara luas tempat yang ditutupi oleh spesies tumbuhan dengan luas total habitat. Luas penutupan dapat dinyatakan dengan menggunakan luas bidang dasar (basal area).

$$
\begin{aligned}
& \text { Dominansi }(D)=\frac{\Sigma \text { bidang dasar suatu jenis }}{\text { luas plot contoh }} \\
& \text { Dominansi Relatif }(D R)=\frac{\text { dominansi suatu jenis }}{\text { dominansi seluruh jenis }} \times 100 \%
\end{aligned}
$$

c) Indeks nilai penting (INP)

INP atau importance value index (IVI) adalah parameter kuantitatif yang dapat dipakai untuk menyatakan fase dominansi atau penguasahaan spesiesspesies dalam suatu komunitas tumbuhan dengan kriteria semakin tinggi nilai INP suatu spesies, semakin dominan atau berkuasa suatu spesies dalam suatu komunitas tumbuhan.

Rumus INP adalah:

$\mathrm{INP}=\mathrm{KR}(\%)+\mathrm{FR}(\%)+\mathrm{DR}(\%)$ (untuk fase dewasa yaitu, tiang dan pohon)
$\mathrm{INP}=\mathrm{KR}(\%)+\mathrm{FR}(\%)$ (untuk fase permudaan yaitu, semai dan pancang)

Dimana:

INP $=$ Indeks nilai penting

$\mathrm{KR}=$ Kerapatan relatif

$\mathrm{FR} \quad=$ Frekuensi relatif

DR = Dominansi relatif

d) Luas bidang dasar (LBD)

Luas bidang dasar (LBD) adalah luas penampang lingkaran diameter batang. Rumus untuk menghitung LBD adalah:

$$
\operatorname{LBD}=1 / 4 \pi(d)^{2}
$$

Dimana:

$$
\begin{aligned}
\text { LBD } & =\text { Luas bidang dasar }\left(\mathrm{m}^{2}\right) \\
1 / 4 \pi & =\operatorname{Konstanta}(\mathrm{m}) \\
\mathrm{D} & =\text { Diameter }(\mathrm{m})
\end{aligned}
$$




\section{Analisis Data}

Data yang diperoleh kemudian dianalisis secara tabulasi dan ditampilkan dalam bentuk tabel, grafik dan gambar.

\section{HASIL DAN PEMBAHASAN}

\section{Komposisi Tumbuhan Berkayu}

Jenis tumbuhan berkayu yang ditemukan pada kawasan hutan dataran rendah CA Pegunungan Wondiwoi di Kampung Dotir sebanyak 260 jenis tumbuhan berkayu yang tergolong dalam 57 famili, terdiri dari fase pertumbuhan semai sebanyak 168 jenis, pancang 172 jenis, tiang 138 jenis dan pohon 136 jenis tumbuhan berkayu. Famili yang mendominasi pada keseluruhan fase pertumbuhan adalah Moraceae. Pada fase pertumbuhan semai sebanyak 52 famili yang didominan Moraceae, fase pertumbuhan pancang 51 famili yang didominan Moraceae, fase pertumbuhan tiang 39 famili yang didominan Euphorbiaceae dan fase pertumbuhan pohon 39 famili yang didominan Euphorbiaceae, dapat dilihat pada Gambar 1.

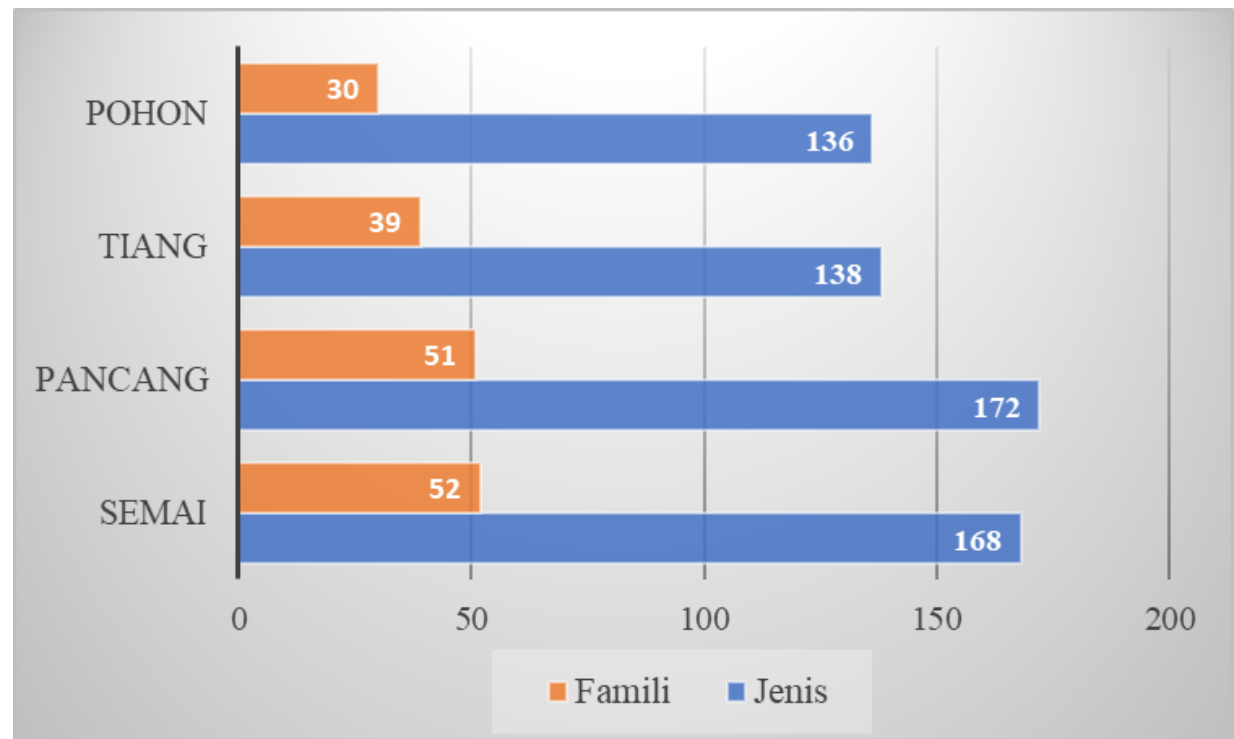

Gambar 2. Jumlah jenis dan famili tumbuhan berkayu pada hutan dataran rendah CA Pegunungan Wondiwoi

Terlihat bahwa jumlah jenis tumbuhan berkayu pada fase pertumbuhan pancang kawasan hutan dataran rendah CA Pegunungan Wondiwoi di Kampung Dotir lebih banyak bila dibandingkan dengan fase pertumbuhan yang lain. Hal ini dikarenakan rapatnya tajuk pohon pada kawasan hutan dataran rendah CA Pegunungan Wondiwoi. Tajuk pohon hutan hujan tropis sangat rapat, ditambah lagi adanya tumbuhan yang memanjat, menggantung dan menempel pada dahan - dahan pohon, misalnya rotan, anggrek dan jenis paku - pakuan. Hal ini menyebabkan sinar matahari tidak dapat menembus tajuk hutan hingga ke lantai hutan, sehingga tidak memungkinkan bagi semak untuk berkembang di bawah naungan tajuk pohon kecuali spesies tumbuhan yang telah beradaptasi dengan 
baik untuk tumbuh di bawah naungan (Arief 1994; Indriyanto 2010). Hal ini yang membuat tumbuhan pada fase pertumbuhan pancang lebih banyak dibandingkan dengan tumbuhan pada fase pertumbuhan semai. Rapatnya tajuk akan membuat jumlah jenis pada fase pertumbuhan pancang akan lebih banyak dari fase pertumbuhan lainnya (Euwsi 1990). Sedangkan jumlah famili fase pertumbuhan semai pada kawasan hutan dataran rendah $\mathrm{CA}$ Pegunungan Wondiwoi lebih banyak dibandingkan dengan fase pertumbuhan lainnya. Hal tersebut menandakan pertumbuhannya normal, karena jumlah famili akan berbanding lurus dengan jumlah famili.

\section{Struktur Tumbuhan Berkayu}

\section{Semai}

Pada fase pertumbuhan semai terdapat 168 jenis tumbuhan berkayu. Jenis yang paling dominan adalah Pometia pinnata dan yang memliki nilai INP terendah adalah Cynometra sp. Jenis - jenis tumbuhan berkayu dominan tersebut selengkapnya dapat dilihat pada tabel 1 .

Tabel 1. Sepuluh jenis tumbuhan berkayu dominan pada fase pertumbuhan semai di kawasan hutan dataran rendah CA Pegunungan Wondiwoi di Kampung Dotir

\begin{tabular}{lllccccc}
\hline No. & \multicolumn{1}{c}{ Nama Latin } & \multicolumn{1}{c}{ Famili } & $\begin{array}{c}\text { K } \\
(\mathrm{n} / \mathrm{ha})\end{array}$ & $\begin{array}{c}\text { KR } \\
(\%)\end{array}$ & F & $\begin{array}{c}\text { FR } \\
(\%)\end{array}$ & $\begin{array}{c}\text { INP } \\
(\%)\end{array}$ \\
\hline 1 & Pometia pinnata & Sapindaceae & 3119 & 6.501 & 0.390 & 4.745 & 11.247 \\
2 & Pimelodendron amboinicum & Euphorbiaceae & 2286 & 4.764 & 0.295 & 3.588 & 8.352 \\
3 & Canarium hirsutum & Burceraceae & 1571 & 3.275 & 0.219 & 2.662 & 5.937 \\
4 & Macaranga mappa & Euphorbiaceae & 1452 & 3.027 & 0.143 & 1.736 & 4.763 \\
5 & Gymnacranthera farquhariana & Myristicaceae & 1071 & 2.233 & 0.200 & 2.431 & 4.664 \\
6 & Koordersiodendron pinatum & Anacardiaceae & 1095 & 2.283 & 0.190 & 2.315 & 4.598 \\
7 & Pometia coreacea & Sapindaceae & 1405 & 2.928 & 0.124 & 1.505 & 4.433 \\
8 & Lepiniopsis ternatensis & Apocynaceae & 1238 & 2.581 & 0.152 & 1.852 & 4.432 \\
9 & Macaranga aleurytoides & Euphorbiaceae & 1143 & 2.382 & 0.143 & 1.736 & 4.118 \\
10 & Antiaris toxicaria & Moraceae & 905 & 1.886 & 0.171 & 2.083 & 3.969 \\
\hline
\end{tabular}

Sumber : Data primer 2016

Dari tabel 1 menunjukkan bahwa jenis tumbuhan berkayu pada fase pertumbuhan semai yang paling dominan adalah Pometia pinnata dengan INP tertinggi $11,247 \%$. Jenis ini merupakan jenis dominan pada fase pertumbuhan semai karena memiliki jumlah individu yang sangat banyak dan penyebaran individu yang sangat merata. Pimelodendron amboinicum merupakan jenis dominan kedua dengan INP 8,352\%, Canarium hirsutum merupakan jenis dominan ketiga dengan INP 5,937\%, kedua jenis ini menjadi dominan kedua dan ketiga karena pada fase pertumbuhan semai juga karena memiliki jumlah individu yang cukup banyak dan penyebaran individu yang cukup merata, Macaranga mappa merupakan jenis keempat dengan INP 4,763\% karena memiliki individu yang cukup merata.

Pada tabel 1 dapat dilihat Pometia coreacea berada pada dominan urutan kedelapan dengan INP 4,433\%, namun memiliki jumlah individu yang lebih banyak bila dibandingkan dengan 
Gymnacranthera farquhariana yang berada pada dominan kelima dengan INP $4,664 \%$ dan Koordersiodendron pinatum berada pada dominan keenam dengan INP 4,598\%. Dapat dikatakan Pometia coreacea memiliki kecepatan perkecambahan biji yang lebih baik bila dibandingkan dengan kedau jenis tersebut, namun Gymnacranthera farquhariana dan Koordersiodendron pinatum memiliki penyebaran individu yang lebih merata dari Pometia coreacea. Penyebaran individu Pometia coreacea yang lebih rendah bila dibandingkan dengan kedua jenis tersebut menunjukan bahwa adanya persaingan antarindividu dari jenis Pometia coreacea pada kawasan hutan dataran rendah CA Pegunungan Wondiwoi.

Selain jenis - jenis tumbuhan berkayu pada fase pertumbuhan semai yang memiliki INP tertinggi, terdapat pula beberapa jenis yang memiliki nilai INP terandah. Jenis - jenis tumbuhan berkayu yang memiliki INP terendah pada fase pertumbuhan semai secara lengkap dapat dilihat pada tabel 2 .

Tabel 2. Lima jenis tumbuhan berkayu dengan INP terendah pada fase pertumbuhan semai di kawasan hutan CA Pegunungan Wondiwoi di Kampung Dotir

\begin{tabular}{lllccccc}
\hline No. & \multicolumn{1}{c}{ Nama Latin } & \multicolumn{1}{c}{ Famili } & $\begin{array}{c}\text { K } \\
(\mathrm{n} / \mathrm{ha})\end{array}$ & $\begin{array}{c}\text { KR } \\
(\%)\end{array}$ & F & $\begin{array}{c}\text { FR } \\
(\%)\end{array}$ & $\begin{array}{c}\text { INP } \\
(\%)\end{array}$ \\
\hline 164 & Polyalthia glauca & Annonaceae & 24 & 0.050 & 0.010 & 0.116 & 0.165 \\
165 & Semecarpus papuanus & Anacardiaceae & 24 & 0.050 & 0.010 & 0.116 & 0.165 \\
166 & Semecarpus sp1. & Anacardiaceae & 24 & 0.050 & 0.010 & 0.116 & 0.165 \\
167 & Semecarpus forstenii & Anacardiaceae & 24 & 0.050 & 0.010 & 0.116 & 0.165 \\
168 & Cynometra sp. & Fabaceae & 24 & 0.050 & 0.010 & 0.116 & 0.165 \\
\hline
\end{tabular}

Sumber : Data primer 2016

Tabel 2 nampak bahwa kelima jenis yang memiliki INP terendah pada fase pertumbuhan semai adalah Polyalthia glauca, Semecarpus papuanus, Semecarpus sp1., Semecarpus forstenii dan Cynometra sp. Kelima jenis tersebut merupakan jenis yang memiliki INP terendah $0,165 \%$ karena memiliki jumlah individu yang sangat sedikit dan penyebaran individu yang sangat tidak merata di lokasi penelitian. Menurut Vickery (1984) faktor yang mempengaruhi yang dapat berpengaruh terhadap keberlangsungan hidup spesies spesies tertentu adalah kehadiran hewan penyerbuk, agen dispersal biji, kondisi tanah, kelembapan tanah dan udara, angin dan gangguan kerusakan lingkungan oleh manusia.

Kelima jenis tersebut merupakan jenis yang rawan untuk punah pada lokasi penelitian atau dapat dinyatakan sebagai jenis yang rawan untuk punah secara ekologi pada lokasi penelitian. Untuk mencegah terjadinya kepunahan sangat diperlukan adanya konservasi terhadap ke 5 jenis tersebut, baik konservasi ex-situ maupun konservasi in-situ.

\section{Pancang}

Pada fase pertumbuhan pancang terdapat 172 jenis tumbuhan berkayu. Jenis yang paling dominan pada fase pertumbuhan pancang adalah Pometia pinnata dan jenis yang memiliki INP terendah adalah Toona sureni. Jenis-jenis 
tumbuhan berkayu fase pertumbuhan lengkap dapat dilihat pada tabel 3. pancang yang dominan tersebut secara

Tabel 3. Sepuluh jenis tumbuhan berkayu dominan pada fase pertumbuhan pancang di kawasan hutan dataran rendah CA Pegunungan Wondiwoi di Kampung Dotir

\begin{tabular}{cllccccc}
\hline \multirow{2}{*}{ No. } & \multicolumn{1}{c}{ Nama Latin } & \multicolumn{1}{c}{ Famili } & $\begin{array}{c}\mathrm{K} \\
(\mathrm{n} / \mathrm{ha})\end{array}$ & $\begin{array}{c}\mathrm{KR} \\
(\%)\end{array}$ & F & $\begin{array}{c}\text { FR } \\
(\%)\end{array}$ & $\begin{array}{c}\text { INP } \\
(\%)\end{array}$ \\
\hline 1 & Pometia pinnata & Sapindaceae & 272 & 5.574 & 0.362 & 4.153 & 9.727 \\
2 & Pimelodendron amboinicum & Euphorbiaceae & 170 & 3.475 & 0.314 & 3.607 & 7.082 \\
3 & Gnetum genemon & Gnetaceae & 154 & 3.148 & 0.276 & 3.169 & 6.317 \\
4 & Gymnacranthera farquhariana & Myristicaceae & 170 & 3.475 & 0.238 & 2.732 & 6.208 \\
5 & Horsfieldia laevigata & Myristicaceae & 67 & 1.377 & 0.295 & 3.388 & 4.765 \\
6 & Endiandra rubescens & Lauraceae & 118 & 2.426 & 0.200 & 2.295 & 4.721 \\
7 & Medusanthera laxiflora & Stemunuraceae & 125 & 2.557 & 0.171 & 1.967 & 4.525 \\
8 & Macaranga aleurytoides & Euphorbiaceae & 141 & 2.885 & 0.124 & 1.421 & 4.306 \\
9 & Canarium hirsitum & Burceraceae & 96 & 1.967 & 0.181 & 2.076 & 4.044 \\
10 & Aglaia odorata & Meliaceae & 99 & 2.033 & 0.171 & 1.967 & 4.000 \\
\hline
\end{tabular}

Sumber : Data primer 2016

Tabel 3 menunjukkan bahwa Pometia pinnata memiliki nilai INP 9,727\% merupakan jenis dominan pada fase pertumbuhan semai ternyata masih merupakan jenis yang paling dominan pada fase pertumbuhan pancang. Hal ini disebabkan karena jenis ini memiliki jumlah individu yang sangat banyak dan penyebaran individu yang sangat merata di lokasi penelitian. Jenis dominan kedua adalah Pimelodendron amboinicum memiliki nilai INP 7,082\%, karena memiliki jumlah individu yang banyak dan penyebaran individu yang merata. Jenis dominan ketiga adalah Gnetum gnemon, karena penyebaran individunya yang cukup merata pada lokasi penelitian.

Pada tabel 3 dapat dilihat Macaranga aleurytoides berada pada dominan kedelapan dengan nilai INP 4,306\% namun memiliki jumlah individu yang banyak bila dibandingankan dengan Horsfieldia laevigata dengan INP 4,765\%, Endiandra dengan INP 4,721\%, Medusanthera laxiflora dengan INP
4,525\%. Jumlah individu pada jenis Macaranga aleurytoides lebih banyak kerena jenis ini merupakan salah satu jenis tumbuhan Pionir atau cepat tumbuh (fast growing), namun penyabaran individu jenis ini kurang merata bila dibandingkan dengan ketiga jenis tersebut karena tumbuhan fast growing sangat membutuhkan matahari sehingga umumnya tumbuh pada daerah - daerah terbuka. Kondisi ini yang menyebabkan penyebaran individu dari jenis Macaranga aleurytoides kurang merata. Selain itu kemampuan beradaptasi Macaranga aleurytoides juga kurang baik pada lokasi penelitian hutan dataran rendah CA Pegunungan Wondiwoi di Kampung Dotir.

Jumlah individu yang sedikit dan penyebaran yang tidak merata membuat beberapa jenis dari tumbuhan berkayu memiliki INP terendah dan menjadi sedikit saat mencapai fase pertumbuhan pancang. Keterangan mengenai jenis - 
jenis dengan INP terendah secara lengkap dapat dilihat pada tabel 4.

Tabel 4. Lima jenis tumbuhan berkayu dengan INP terendah pada fase pertumbuhan pancang di kawasan hutan CA Pegunungan Wondiwoi di Kampung Dotir

\begin{tabular}{lllccccc}
\hline No. & \multicolumn{1}{c}{ Nama Latin } & Famili & $\begin{array}{c}\text { K } \\
(\mathrm{n} / \mathrm{ha})\end{array}$ & $\begin{array}{c}\text { KR } \\
(\%)\end{array}$ & F & $\begin{array}{r}\text { FR } \\
(\%)\end{array}$ & $\begin{array}{c}\text { INP } \\
(\%)\end{array}$ \\
\hline 168 & Pterocymbium beccari & Malvaceae & 3 & 0.066 & 0.010 & 0.109 & 0.175 \\
169 & Sterculia shillinglawi & Malvaceae & 3 & 0.066 & 0.010 & 0.109 & 0.175 \\
170 & Streblus elongate & Moraceae & 3 & 0.066 & 0.010 & 0.109 & 0.175 \\
171 & Syzygium sp3. & Myrtaceae & 3 & 0.066 & 0.010 & 0.109 & 0.175 \\
172 & Toona sureni & Meliaceae & 3 & 0.066 & 0.010 & 0.109 & 0.175 \\
\hline
\end{tabular}

Sumber : Data primer 2016

Dari tabel 4 menunjukan bahwa kelima jenis yang memiliki INP terendah pada fase pertumbuhan pancang adalah Pterocymbium beccarii, Sterculia shillinglawii, Streblus elongata, Syzygium sp3. dan Toona Sureni. Kelima jenis tersebut merupakan jenis yang memiliki INP terendah karena memiliki jumlah individu yang sangat sedikit dan penyebaran individu yang sangat tidak merata di lokasi penelitian. Seperti yang telah dijelaskan pada fase pertumbuhan semai, jenis - jenis yang memiliki INP terendah pada fase pertumbuhan pancang dapat dipengaruhi oleh kehadiran hewan penyerbuk, agen dispersal biji, kondisi tanah, kelembapan tanah dan udara, angin dan gangguan atau kerusakan lingkungan yang disebabkan oleh manusia.

Tabel 5. Sepuluh jenis tumbuhan berkayu dominan pada fase pertumbuhan tiang di kawasan hutan dataran rendah CA Pegunungan Wondiwoi di Kampung Dotir

\begin{tabular}{cllllll}
\hline No. & \multicolumn{1}{c}{ Nama Latin } & \multicolumn{1}{c}{ Famili } & $\begin{array}{c}\text { KR } \\
(\%)\end{array}$ & $\begin{array}{c}\text { FR } \\
(\%)\end{array}$ & $\begin{array}{c}\text { DR } \\
(\%)\end{array}$ & $\begin{array}{c}\text { INP } \\
(\%)\end{array}$ \\
\hline 1 & Litsea timoriana & Lauraceae & 4.745 & 4.661 & 5.197 & 14.603 \\
2 & Pometia pinnata & Sapindaceae & 5.292 & 3.602 & 5.185 & 14.079 \\
3 & Pimelodendron amboinicum & Euphorbiaceae & 3.285 & 3.602 & 3.153 & 10.040 \\
4 & Medusanthera laxiflora & Stemunuraceae & 3.285 & 3.390 & 3.151 & 9.826 \\
5 & Gymnacranthera farquhariana & Myristicaceae & 3.102 & 3.390 & 3.242 & 9.734 \\
6 & Stemonurus javanicum & Stemunuraceae & 3.285 & 2.966 & 3.018 & 9.269 \\
7 & Gompandra glabosa & Icacinaceae & 2.555 & 2.754 & 2.066 & 7.375 \\
8 & Pterygota horsfieldii & Malvaceae & 2.372 & 2.331 & 2.412 & 7.115 \\
9 & Cerbera floribunda & Apocynaceae & 2.007 & 1.695 & 2.428 & 6.130 \\
10 & Horsfieldia irya & Myristicaceae & 1.825 & 2.119 & 1.740 & 5.683 \\
\hline Sumber : Data primer 2016 & & & & &
\end{tabular}

Kelima jenis tersebut merupakan jenis yang rawan untuk punah pada fase pertumbuhan pancang di lokasi penelitian atau dapat dinyatakan sebagai jenis yang rawan untuk punah secara ekologi pada lokasi penelitian. Untuk mencegah 
terjadinya kepunahan sangat diperlukan adanya konservasi terhadap ke 5 jenis tersebut, baik konservasi ex-situ maupun konservasi in-situ.

\section{Tiang}

Pada fase pertumbuhan terdapat 138 jenis tumbuhan berkayu. Jenis yang dominan pada fase pertumbuhan tiang adalah Litsea timoriana dan jenis tumbuhan berkayu yang memiliki INP terendah adalah Syzygium sp1. Jenis jenis tumbuhan berkayu yang dominan pada fase pertumbuhan tiang dapat dilihat pada tabel 5.

Dari tabel 5 menunjukan bahwa Litsea timoriana merupakan jenis yang paling dominan pada fase pertumbuhan tiang dengan INP 14,603\%. Jenis ini ternyata bukan jenis dominan pada fase pertumbuhan semai dan pancang. Jenis Litsea timoriana dominan pada fase pertumbuhan tiang karena memiliki penyebaran individu yang sangat merata, areal tempat tumbuh yang luas dan ratarata pertumbuhan diameter yang sangat baik. Pometia pinnata merupakan jenis dominan kedua dengan INP 14,079\%, karena memiliki jumlah individu yang banyak, areal tempat tumbuh yang cukup luas dan rata - rata pertumbuhan diameter yang baik.

Gymnacranthera farquhariana merupakan jenis dominan kelima dengan nilai INP 9,734\%, namun memiliki nilai dominansi yang lebih tinggi bila dibandingkan dengan Pimelodendron amboinicum yang berada pada dominan ketiga dengan INP 10,040 \% dan Medusanthera laxifola yang berada pada dominan keempat dengan INP 9,826\%. Nilai dominansi yang tinggi dikarenakan Gymnacranthera farquhariana memiliki rata - rata pertumbuhan diameter yang lebih baik. Namun jumlah individu yang cukup banyak dan penyebaran individu yang cukup merata dari Pimelodendron amboinicum dan Medusanthera laxiflora lebih baik dari Gymnacranthera faquhariana. Kondisi ini yang membuat kedua jenis tersebut lebih dominan dibandingkan dengan Gymnacranthera farquhariana. Keadaan seperti juga terjadi pada jenis Cerbera floribunda yang berada pada dominan kesembilan dengan INP $6,130 \%$, namun memiliki nilai dominansi yang lebih besar bila dibandingkan dengan Pterygita horsfieldii yang berada pada dominan kedelapan dengan INP 7,115\% dan Gompandra glabosa yang berada pada dominan ketujuh dengan INP 7,375\%.

Jumlah individu yang sangat sedikit, penyebaran yang tidak merata dan pertumbuhan diameter yang lambat membuat beberapa dari jenis tumbuhan berkayu memiliki nilai INP yang rendah dan menjadi sedikit saat mencapai fase pertumbuhan tiang. Jenis - jenis tumbuhan berkayu dengan INP terendah secara lengkap dapat dilihat pada tabel 6 .

Tabel 6 menunjukan bahwa kelima jenis yang memiliki INP terendah pada fase pertumbuhan tiang adalah Kleinhovia hospita, Ficus sp2., Gnetum gnemon, Hopea papuana dan Syzygium sp1. Kelima jenis tersebut merupakan jenis yang memiliki INP terendah karena memiliki jumlah individu yang sangat sedikit, penyebaran individu yang sangat tidak merata dan rata-rata pertumbuhan diameter yang kurang baik di lokasi penelitian. 
Tabel 6. Lima jenis tumbuhan berkayu dengan INP terendah pada fase pertumbuhan tiang di kawasan hutan CA Pegunungan Wondiwoi di Kampung Dotir

\begin{tabular}{lllcccc}
\hline No. & \multicolumn{1}{c}{ Nama Latin } & \multicolumn{1}{c}{ Famili } & $\begin{array}{c}\text { KR } \\
(\%)\end{array}$ & $\begin{array}{c}\text { FR } \\
(\%)\end{array}$ & $\begin{array}{c}\text { DR } \\
(\%)\end{array}$ & $\begin{array}{c}\text { INP } \\
(\%)\end{array}$ \\
\hline 134 & Klenhofia hospital & Euphorbiaceae & 0.182 & 0.212 & 0.088 & 0.482 \\
135 & Ficus sp 2. & Moraceae & 0.182 & 0.212 & 0.088 & 0.482 \\
136 & Gnetum gnemon & Gnetaceae & 0.182 & 0.212 & 0.088 & 0.482 \\
137 & Hopea papuana & Diptherocarpaceae & 0.182 & 0.212 & 0.088 & 0.482 \\
138 & Syzygium spl. & Myrtaceae & 0.182 & 0.212 & 0.088 & 0.482 \\
\hline
\end{tabular}

Sumber : Data primer 2016

Kelima jenis tersebut merupakan jenis yang rawan untuk punah pada fase pertumbuhan tiang di lokasi penelitian atau dapat dinyatakan sebagai jenis yang rawan untuk punah secara ekologi pada lokasi penelitian. Untuk mencegah terjadinya kepunahan sangat diperlukan adanya konservasi terhadap ke 5 jenis tersebut, baik konservasi ex-situ maupun konservasi in-situ.

\section{Pohon}

Pada fase pertumbuhan pohon terdapat 136 jenis tumbuhan berkayu. Jenis pada fase pertumbuhan yang paling dominan adalah Pometia pinnata dan jenis tumbuhan berkayu fase pertumbuhan pohon yang memiliki INP terendah adalah Syzygium sp3. Jenis- jenis tumbuhan berkayu yang dominan pada fase pertumbuhan pohon secara lengkap dapat dilihat pada tabel 7 .

Tabel 7. Sepuluh jenis tumbuhan berkayu dominan pada fase pertumbuhan pohon di kawasan hutan dataran rendah CA Pegunungan Wondiwoi di Kampung Dotir

\begin{tabular}{cllcccc}
\hline \multirow{2}{*}{ No. } & \multicolumn{1}{c}{ Nama Latin } & \multicolumn{1}{c}{ Famili } & $\begin{array}{c}\text { KR } \\
(\%)\end{array}$ & $\begin{array}{c}\text { FR } \\
(\%)\end{array}$ & $\begin{array}{c}\text { DR } \\
(\%)\end{array}$ & $\begin{array}{c}\text { INP } \\
(\%)\end{array}$ \\
\hline 1 & Pometia pinnata & Sapindaceae & 7.123 & 6.086 & 7.039 & 20.248 \\
2 & Pimelodendron amboinicum & Euphorbiaceae & 6.301 & 5.921 & 4.774 & 16.996 \\
3 & Alstonia scholaris & Apocynaceae & 4.110 & 3.947 & 6.682 & 14.739 \\
4 & Koordersiodendron pinnatum & Anacardiaceae & 3.288 & 3.454 & 7.536 & 14.278 \\
5 & Pterygota horsfieldii & Malvaceae & 2.740 & 2.632 & 6.533 & 11.904 \\
6 & Artocarpus cempedens & Moraceae & 3.014 & 2.467 & 2.940 & 8.421 \\
7 & Litsea timoriana & Lauraceae & 3.288 & 2.796 & 1.976 & 8.060 \\
8 & Octomeles sumatrana & Datiscaceae & 1.644 & 1.809 & 4.120 & 7.573 \\
9 & Artocarpus altilis & Moraceae & 2.329 & 2.138 & 2.834 & 7.301 \\
10 & Pometia acuminate & Sapindaceae & 1.644 & 1.645 & 3.671 & 6.959 \\
\hline Sumber & Data primer 2016 & & & & &
\end{tabular}

Sumber : Data primer 2016

Fase pertumbuhan pohon merupakan tahap akhir dari suksesi pada hutan alam. Tabel 7 nampak bahwa Pometia pinnata merupakan jenis yang dominan pada fase pohon dengan INP 20,248\%. Jenis ini pada fase pertumbuhan semai dan 
pancang merupakan jenis yang paling dominan kemudian pada fase tiang merupakan jenis dominan kedua. Jenis ini dominan pada fase pohon karena memiliki jumlah individu yang sangat banyak, penyebaran individu yang sangat merata dan rata-rata pertumbuhan riap diameter yang sangat baik. Pimelodendron amboinicum merupakan jenis dominan kedua pada fase pertumbuhan pohon dengan INP $16,996 \%$, karena memiliki jumlah individu dan penyebaran individu yang merata. Sedangkan jenis dominan ketiga adalah Alstonia scholaris, karena memiliki jumlah individu yang cukup banyak, penyebaran individu yang cukup merata dan rata - rata pertumbuhan diameter yang cukup baik.

Koordersiodendron pinatum adalah jenis dominan keempat dengan INP $14,278 \%$ karena jumlah individunya yang cukup banyak, penyebarannya yang cukup merata dan rata - rata pertumbuhan diameter yang sangat baik. Dapat dilihat pada table 7, nilai dominansi relatif dari Koordersiodendron pinatum sangat tinggi bila dibandingkan dengan kesepuluh jenis dominan lainnya. Hal ini dikarenakan Koordersiodendron pinatum dapat beradaptasi dengan baik pada lokasi tempat tumbuh, sehingga rata - rata pertumbuhan diameternya sangat baik.

Litsea timoriana merupaka jenis yang dominan pada fase pertumbuhan tiang, namun pada fase pertumbuhan pohon Litsea timoriana berada pada dominan ketujuh dengan INP 8,060\%, yang terlihat dari nilai dominansi relatif Litsea timoria yang sangat rendah bila dibandingkan dengan sepuluh jenis dominan lainnya. Jumlah dan penyebaran individu dari Pterygota horsfieldii yang berada pada dominan kelima dengan INP 11,904\% dan Artocarpus cempedens yang berada pada dominan keenam dengan INP 8,421 $\%$ lebih banyak dan lebih merata dari Litsea timoriana. Hal ini mengindikasikan bahwa adanya persaingan terhadap ruang dan waktu antara Litsea timoriana dan jenis-jenis tumbuhan berkayu lainnya sehingga pertumbuhan diameternya menjadi lambat saat mencapai fase pertumbuhan pohon (Ewusie 1990).

Akibat dari persaingan antar ruang dan waktu sehingga banyak jenis - jenis tumbuhan berkayu yang dapat bertahan hidup hingga fase pertumbuhan pohon dan memiliki nilai INP rendah. Jenis jenis tumbuhan berkayu fase pertumbuhan pohon dengan INP terendah secara lengkap dapat dilihat pada tabel 8 .

Tabel 8. Lima jenis tumbuhan berkayu dengan INP terendah pada fase pohon di kawasan hutan CA Pegunungan Wondiwoi di Kampung Dotir

\begin{tabular}{lllllll}
\hline No. & \multicolumn{1}{c}{ Nama Latin } & Famili & $\begin{array}{c}\text { KR } \\
(\%)\end{array}$ & $\begin{array}{c}\text { FR } \\
(\%)\end{array}$ & $\begin{array}{l}\text { DR } \\
(\%)\end{array}$ & $\begin{array}{l}\text { INP } \\
(\%)\end{array}$ \\
\hline 132 & Oxmosylon globulare & Araliaceae & 0.137 & 0.164 & 0.041 & 0.343 \\
133 & Platea sp. & Icacinaceae & 0.137 & 0.164 & 0.041 & 0.343 \\
134 & Policias nodosa & Araliaceae & 0.137 & 0.164 & 0.041 & 0.343 \\
135 & Sterculia urceolata & Malvaceae & 0.137 & 0.164 & 0.041 & 0.343 \\
136 & Syzygium sp3. & Myrtaceae & 0.137 & 0.164 & 0.041 & 0.343 \\
\hline
\end{tabular}

Sumber : Data primer 2016 
Dari tabel 8 menunjukan bahwa kelima jenis yang memiliki INP terendah pada fase pertumbuhan tiang adalah Osmoxylon globulare, Platea indica, Polycias nodosa, Sterculia urceolata dan Syzygium sp3. Kelima jenis tersebut merupakan jenis yang memiliki INP terendah pada fase pertumbuhan pohon karena memiliki jumlah individu yang sangat sedikit, penyebaran individu yang sangat tidak merata dan rata - rata pertumbuhan riap diameter yang kurang baik di lokasi penelitian. Selain itu persaingan antar ruang dan waktu dari jenis - jenis yang memiliki INP terendah dengan jenis - jenis tumbuhan berkayu lainnya dan juga dapat dipengaruhi oleh aktifitas manusia dalam pemanfaatan lahan sebagai kebun dan kebakaran hutan.

Kelima jenis tersebut merupakan jenis yang rawan untuk punah pada fase pohon di lokasi penelitian atau dapat dinyatakan sebagai jenis yang rawan untuk punah secara ekologi pada lokasi penelitian. Untuk mencegah terjadinya kepunahan sangat diperlukan adanya konservasi terhadap ke 5 jenis tersebut, baik konservasi ex-situ maupun konservasi insitu.

\section{DAFTAR PUSTAKA}

Arief A. 1994. Hutan hakikat dan pengaruhnya terhadap lingkungan. Yayasan Obor Indonesia. Jakarta.

Arifin. 2001. Hutan dan kehutanan. Kanisius. Yogyakarta.

Badan Pusat Statistik. 2015. Kabupaten Teluk Wondama dalam angka. Badan
Pusat Statistik Kabupaten Teluk Wondama.

Balai Besar Konsevasi Sumberdaya Alama Papua Barat. 2011. Buku informasi kawasan konservasi. Sorong. Papua Barat.

Ewusie JY. 1990. Ekologi tropika. ITB. Bandung.

Indriyanto. 2006. Ekologi hutan. PT. Bumi Aksara. Jakarta.

John R. 1997. Common forest tree of Irian Jaya, Papua - Indonesia. Royal Bataniacal Garden, Kew, Inggris.

Kementerian Kehutanan 2014. Keputusan Menteri Kehutanan RI Nomor SK.783/Menhut-II tentang Kawasan Hutan Provinsi Papua Barat. Kementerian Kehutanan Republik Indonesia.

Kusmana C. $1997 . \quad$ Metode Survei vegetasi. IPB Press. Bogor.

Lekitoo K, Peday HFZ, Panambe N and Cabuy RL. 2017. Ecological and ethnobotanical facet of 'Kelapa Hutan' (Pandanus spp.) and perspectives towards its existence and benefit. International Journal of Botany, 13: 103-114.

Soerianegara I dan Indrawan A. 2005. Ekologi hutan Indonesia. Bogor: Laboratorium Ekologi Hutan Fakultas Kehutanan - IPB. Bogor.

Soerianegara I dan A, Indrawan. 1982. Ekologi hutan Indonesia. Departemen Manajemen Hutan Fakultas Kehutanan Institut Pertanian Bogor. Bogor.

Vickery ML. 1984. Ecology of tropical plants. John Wiley and Sons. New York HLM. 56-76. Penerbit Yayasan Obor Indonesia. 